\title{
Modeling of educational and creative environment For children with special educational needs
}

\author{
Ekaterina Ivanova $^{1}$, Julia Doncheva ${ }^{2}$ \\ ${ }^{1}$ Ekaterina Ivanova, PhD Student, University of Ruse 'Angel Kanchev', Bulgaria \\ ${ }^{2}$ Julia Doncheva, PhD, Assoc. Prof., University of Ruse ‘Angel Kanchev', Bulgaria \\ ${ }^{3}$ University of Ruse, Bulgaria \\ Ekaterina Ivanova
}

\begin{abstract}
.
In the present scientific paper one of the most general aims is the complex health of the child with special educational needs (SEN), its full integration, as far as possible, that contributes to the well-being of the community and its personal happiness. The creative approach to the formation of a developing educational and creative environment for children with special educational needs is fundamental to their adaptation and socialization, to their full and independent way of life. Analysis of the cognitive and creative functioning of the person increases the probability of building skills to include realistic, evidence-based assessments of situations and to reduce the subjective experience of negative emotion. These skills include identifying cognitive distortions, changing beliefs related to the world and others, and changing behavioral coping strategies. With the development of modern technologies and the transition of human civilization to an information society, the problem of personal adaptability becomes more and more relevant. The adaptation of man to the requirements of the social environment, his experience as a professionally realized and succeeded, identified with the group, with the organization experiencing serious pressure from internal and external factors are present. This report discusses options that alleviate the condition of distress, both in children and in their parents. The practical dimension of this statement is related to seeking a coherent link in the application of creativity as a creative process.
\end{abstract}

Keywords: adaptation; independence; integration; skills; socialization;

\section{Introduction}

This article discusses options that help relieve distress, both in abused children and in their parents. The practical dimension is related to the search for a coherent connection in the application of creativity as a personal development process. A process with a steady trend towards adaptation, socialization, and a full-fledged lifestyle for persons or children with special educational needs.

A fulfilling life skills are the capacity for adaptive and positive behavior that enables people to cope effective with the demands and challenges of daily life. [22] In particular, life skills are a group of psychosocial competences and interpersonal skills that help people make 
informed decisions, solve problems, think critically and creatively, communicate effectively, build healthy and sustainable relationships, be empathetic to others, to lead a healthy and efficient lifestyle, etc. Living skills promote personal actions and relationships with others, as well as actions to change the environment to make it health.

\section{Methods}

2.1. The modeling activity of a process usually implies the need to modify them or to identify a problem's to be corrected. This transformation can be realized (or required) by different ways of integrating both information and communication technologies and resources (ICT), such as the need to modify the process. Change management programs, techniques, or models are desirable, as they will be able to contribute to the processes being successfully implemented in practice.

But there is still something to be improved in this respect, as P. Mihova et al. says: '... more should be thought about easy access to programs and databases, well-developed software products that suggest intuitive application and fast training to work with them and highlighting the possibilities of computerized health information, such as quick access to multiple data, opportunities to generate multiple documents with one entry of information, easy storage of information, easy transfer of information, etc.' [12] With the advancement of technology, the vision of models becomes fully feasible, approaching daily closer to reality.

Modeling process has always been a key aspect of interaction processes, methods and approaches for continuous improvement, development and refinement. Modeling activity affects the processes of upbringing, learning, development (physical, mental, emotional, etc.), which leads to a comprehensive architecture of human individuality with a steady trend towards personal improvement. Process capabilities in the context of other functional systems, data, structures, strategies and et al. create greater opportunities for analyzing and planning change.

The stimulus leads to reaction, purposeful training and upbringing lead to development, and it is, as B. Piriova says: 'Development is a purposeful process in terms of physical and mental manifestations. It is not just an accumulation of individual skills, but a result of the interaction of the different functions that mutually stimulate their functional development. In a sense, it is genetically predetermined and, in most children, certain stages of development are reached at approximately the same age. In this uniformity, however, individual differences leave a significant mark. Individual differences are even more evident if children develop in an environment that stimulates their development'. [16] The effect of the joint process of child stimulation and development can be associated with mental health prevention towards well-being.

Creativity is a developing factor for the human personality. Thanks to creativity we are able to perform adequate actions in the changes of the surrounding world and in case of problems. What's more - creativity not only allows us to respond flexibly, but also turns us into an active generator of change (for practical needs or pleasure) - a human-only quality. Along with the active function of creativity to transform the world, through it and in it the development of the man himself is realized. The creative manifestations of the child may not lead to a new socially significant product in the absolute sense of the word, but they are 
important for the development of the author himself - they develop prerequisites for creativity in solving problems in everyday life, work, innovation in science and art.

Management for a developing educational and creative environment includes not only management, but before that clear, specific, structured planning, management of activities and resources, monitoring of quality, imperativeness and rigor in the application of methods, forms, models, etc. on the activities for the realization of the goals and objectives, concerning inclusive education in the Republic of Bulgaria.

The standardization and definition of children with special educational needs is structured in the Ordinance on Inclusive Education, effective 18.12.2018.

The birth and raising of a special needs' child, some of permanently chronic, outlines the ordeal of parents, especially the mother, to overcome the high stress levels of the so-called toxic stress. The fact is that, regardless of disability, for children with special educational needs (SEN), every single step is a victory, a personal victory, for its parents / guardians, for the educators and carers. Because some of them, such as those with hyperactivity and attention deficit disorder (HADV), are characterized by less targeted control, lower selfregulation, and higher reactivity than their peers. $[1,2,8]$ Unfortunately, there is a stereotype in society that discriminates and categorizes these children / people in one way or another. At the base the formation of stereotypical thinking is based on both cognitive processes and influences arising from the history, culture and structural-functional social interactions between the respective groups. In the categorization of objects, ideas are formed about their group (in-group) and the other group or groups (out-group). What is special about this process is that the differences between members of one's own group and between members of other social groups are minimized, but at the same time the differences between members of the different groups are widening.

Process models for creative activity are processes that, by their nature, are classified together into a model of interaction with in and outside groups. Thus, the process model is a description of a process, at the type or algorithm level. Because the model of the process is of type level, the process is an instance of it. [7] The same process model is used many times to develop many applications and thus has many instances. One possible use of a process model is to prescribe how things should be done, sometimes even as opposed to the process itself, which actually happens. The process model is a rough expectation of what the process will look like. What will be the process will be determined during the actual development of the system of practice-transformation, in the case of creative activity.

Children love to create, to build. In early childhood and pre-school age, it is not the efficiency that matters, but above all, the procedural nature of the activity, in order to have a developing effect. That is, not what the end result or product will be, but the activity of its realization, the stages of 'trial-error', 'learning by doing', application of information. We fully agree with P. Konakchieva, which says the following: 'Children's practice-transforming research activity is always accompanied by extraordinary emotionality. She is particularly involved in the activity. The positive emotions generated by the 'discovery' made are capable of provoking significantly greater efforts to achieve an attractive goal for the small environmentalist. The emotional saturation of children's experimentation leads to an intensification of the development of new motives for activity, which significantly restores the motivational-emotional sphere and ultimately contributes to the formation of the heuristic 
structure of the individual'. [9] In this way, the so-called social competence is formed in the child, which through creativity is aimed at maintaining the effectiveness of social relations.

Some of the process models applied in our country are trying to help children with SEN, to develop their life skills without context, but they are not effective enough to achieve behavioral outcomes because the person-centered approach does not apply to each case. [6] In this aspect, for example, art pedagogy through art therapy has enormous potential in this regard. According to P. Marcheva: 'Modern special pedagogy provides opportunities for early diagnosis of disorders in the development of children and timely organization and implementation of purposeful pedagogical correction. Through the means of art pedagogy, it is possible to reduce the influence of negative tendencies in the development and risks in the social adaptation of the child or student. It is necessary to realize educational and developing art-pedagogical interaction based on the maximum use of stored analyzers, functions and systems of the body, in accordance with the specific nature of developmental defects in children with such, as well as the abilities and skills of those in the norm. This implies the use of special technologies that are reflected in the content and methods of the art-pedagogical process '. [11]

It is necessary to create conditions for the continuous expansion of social experience, and for the latter to create preconditions for the development of mental processes, and through them the internalization. Internalization will assist the process of improving the social status of the individual in the microsocial. In different ages the most active mental processes develop most consistently: in the period of infancy (from birth to 1 year) the emotions develop; early childhood (1-3 years) favors the development of speech; in the pre-school period (3-7 years), perception and memory develop rapidly, and in the primary school age (711 years) - imagination and thinking. Cognitive processes play a leading role in human cognitive activity: sensation, perception, attention, memory, thinking, imagination. Despite the fact that they have their own individual place in this activity, they all interact with each other.

Without attention, whose main function is to organize other processes, it is not possible to perceive and memorize new material. Without perception and memory, the operations of thought and imagination are impossible. For this reason, any psychic purposeful and organized activity, to any psychic process, has consequences for the development of the whole cognitive sphere.

Imagination and creativity in children. Thanks to the imagination we can think of things that we have never even perceived. Imagination is a psychic process in which thinking creates images of certain objects in the path of transformation of reality. It allows the adults to recreate the results of their activities from the very beginning, to anticipate and plan for upcoming events, and to present to the child during the game as a certain image: pilot, sailor, horseback riding, white butterfly, gray bunny and others. Imaginary activity results are the goal of this mental process, and the ways to reach that goal are an algorithm for the activity program. In this way, imagination plays a leading role in the management of a person's activity. The emergence and development of the imagination is closely linked to the formation of other cognitive processes and, above all, thinking. With the accumulation of life experience, thinking becomes more and more based on images. It is because of that the child gains the ability to perform actions in mind. At an early age, it begins to understand that some things can be used to signify and others to serve as substitutes - this is how a symbolic 
function is formed in the mind. Instead of real actions and real things, it begins to use images that describe those actions and things. When a link between a substituted and a designated object is established, it is then for the first time that it becomes possible to imagine - on the story of an adult or on a picture from a book, a specific object, phenomenon or event. This means that its imagination was born. In childhood, imagination is of a reproductive nature and arises involuntarily in the form of impressions received.

These are, first of all, impressions of heard stories, tales, poems, music, films, images, etc. In the imagination, only what gives a strong emotional impression to the child and is of particular interest to him is reproduced. However, at the first steps in its development, imagination is inseparable from the perception of objects and participates with it in the game activity. The child jumps over a wooden stick and imagines himself a rider and the stick a horse. However, he cannot imagine a horse in the absence of a jumping object, and he cannot mentally turn a stick into a horse when not acting on it, when not playing with it. In the game of a 3-4-year-old child, the similarity between the substitute object and the object being replaced (that of reality) is important. For an older child, imagination can capture objects that are not at all similar to the real replaced object. Thus, the need for external support gradually disappears. There is a transition to a mental representation of actions with the subject matter, which is in fact missing and unrelated to the real.

At the age of 5-6 years the child develops a special sensitivity of his imagination. This is the transition from in voluntary memorization and reproduction to arbitrary. This is the basis for the development of creative imagination, enabling the creation of new images. For children with SEN, [14] of course, the processes do not proceed exactly this way, but we make it clear that everything is strictly individual and depends on the disability itself, the degree of disability and the intensity, so systematic and effective work with the child will produce a developing, multiplying and sustainable effect. There are many examples in science, theory and practice in this regard $[3,4,10,18,20,23]$, so the above has been described as good an example of impact in this direction.

Changes and improvements in the child's mentality occur as a result of its activity being carried out or mastered at a given stage. They can be and are most characteristic for any period - early childhood games, role-playing games and creativity in pre-school and elementary school activities. The inclusion in the learning process of games and exercises for the development of cognitive and creative processes and speech, not only promote mental development, but also refine the motor skills, provide speed, meaningful memorization and reproduction of motor actions, self-decision and action in a rapidly changing environment. Even children with no developmental disabilities, if they are not included in the activity for a given period, they may, as a result, be delayed in the development of mental entities, which can lead to retardation and other negative psychic phenomena. This is an essential feature of childhood, which is mediated by the existence of a close link between the various personality traits. For this reason, it is especially important to create favorable conditions for the development of the mentality in accordance with the age characteristics of the child. [17]

\subsection{Results.}

For the purposes of this topic, we conducted a short survey with parents of children with disabilities, a total of 97 . Here we will exhibit some of it. Figure 1 provides a diagram of the answers to the first question. 
Figure 1. Respondents answers diagram on the first question

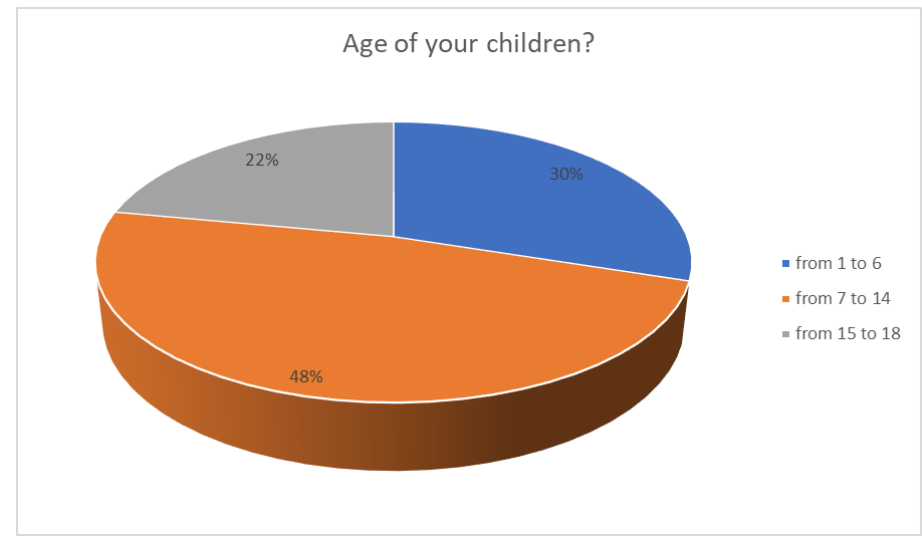

Age of children: (Figure 1) 30\% (29) indicated age from 1 to 6 years, $48 \%$ (47) age from 7 to 14 years and $22 \%$ (21) of respondents indicated age from 15 to 18 years.

The following diagram presents the results of the second question (Figure 2).

Figure 2. Respondents answers diagram on the second question

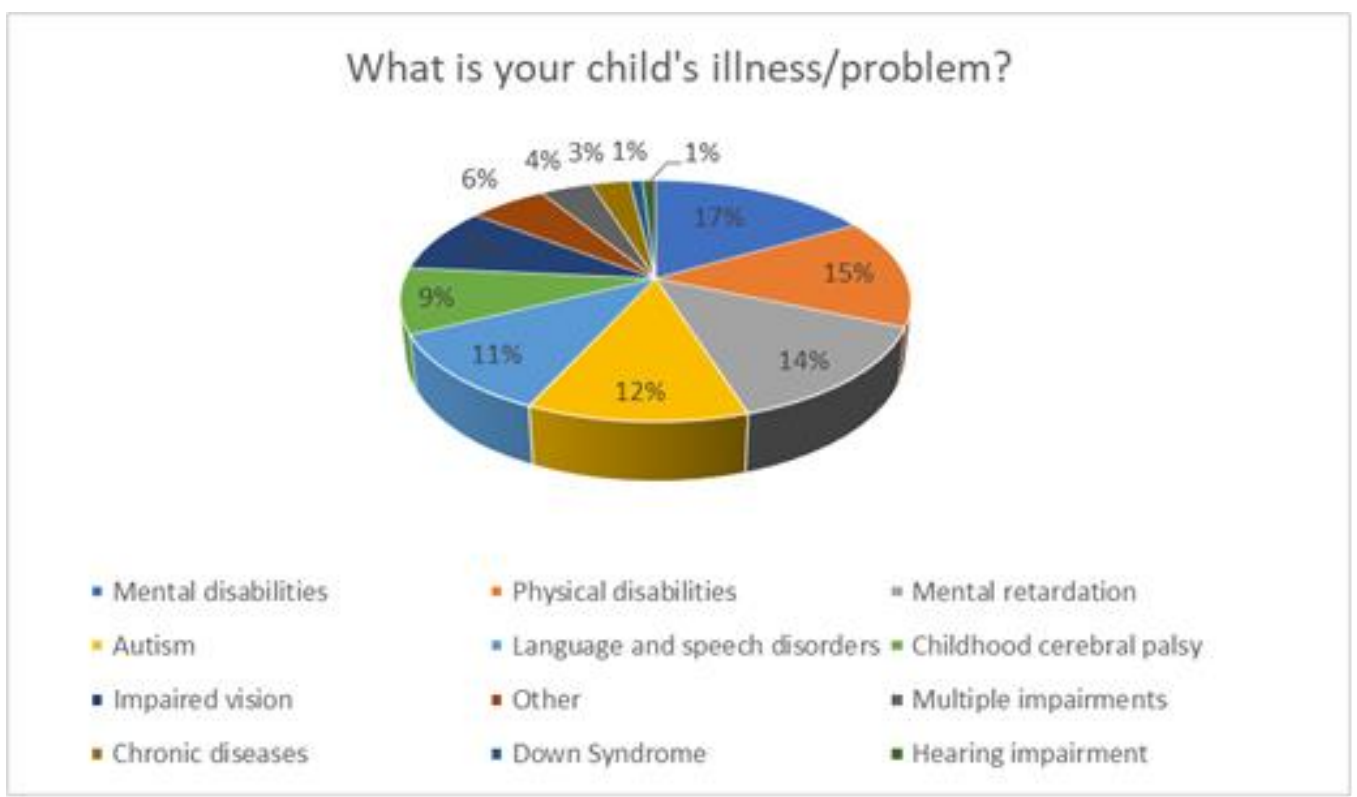

What is your child's illness/problem? is the second question (Figure 2). Of all 97 respondents, $17 \%$ (26) indicated mental disabilities, $15 \%$ (24) indicated physical disabilities, $14 \%$ (22) responded to mental retardation, 12\% (18) with autism, 11\% (17) speech-impaired, 9\% (14) of the respondents indicated childhood cerebral palsy, 9\% (11) with impaired vision, $6 \%$ (9) other, followed by $4 \%$ (6) with multiple impairments, $3 \%$ (4) chronic diseases, $1 \%$ (2) 
with Down syndrome and 1\% (1) with hearing impairment. Some of the participants gave more than one answer.

The answers to the third question are presented in the last diagram (Figure 3).

Figure 3. Respondents answers diagram on the third question

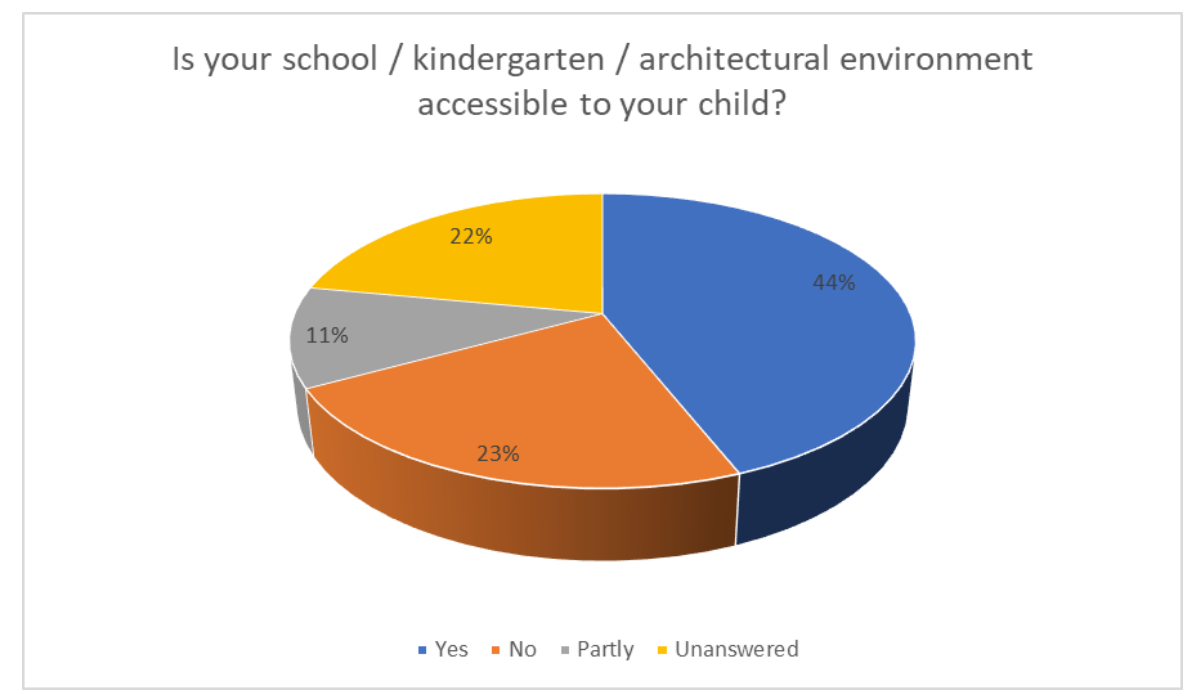

Is your school/kindergarten architectural environment accessible to your child? Of all survey participants, $43(44 \%)$ answered: 'the architectural environment in schools is accessible to students with disabilities', $22(23 \%)$ believe that schools and kindergartens are not accessible to children with disabilities, $21(22 \%)$ are partially available.

One of the major problems of society, which is the subject of much discussion, is the social adaptation of children and adults with special needs. The integration of these persons into society is possible only if a sufficient degree of socio-psychological adaptation is achieved, whose mechanisms are built and developed in the individual process of social ontogeny. The effectiveness of dealing with persons in this category is primarily related not only to the reasons underlying the offense, but also to the internal behavioral bias. In this sense, it is crucial to analyze their socialization process. From a theoretical point of view, meta-process modeling explains the key concepts needed to describe what happens in the development process, what, when it happens, and why. From an operational point of view, metadata modeling aims to provide guidance for methods and application developers. Our and foreign authors $[5,13,19,21]$ examine the commented subject.

In this scholarly publication, we comment on one of the more general goals, namely the complex health of a child with SEN, its full integration, as far as possible, which contributes to the well-being of the community and its own happiness.

\section{Conclusion}

From here, it can be said that the creative approach to the development of educational and creative environment for children with special educational needs is fundamental for their adaptation and socialization, for their full and independent way of life. Analysis of the 
cognitive-creative functioning of the individual increases the likelihood of building skills to incorporate realistic, evidence-based assessments of situations and to reducing the subjective experience of negative emotions. These skills include identifying cognitive distortions, changing beliefs related to the world and others, and changing behavioral coping strategies. With the development of modern technologies and the transition of human civilization to the information society, the problem of adaptive capacities of the individual is becoming more relevant. Adaptation of the person to the requirements of the social environment, its experience as a professionally realized and successful, identified with the group, with the organization experiencing serious pressure from internal and external factors are present.

\section{Acknowledgment}

The study was supported by contract of University of Ruse 'Angel Kanchev', № BG05M2OP001- 2.009-0011-C01,'Support for the development of human resources for research and innovation at the University of Ruse 'Angel Kanchev'. The project is funded with support from the Operational Program 'Science and Education for Smart Growth 2014 2020' financed by the European Social Fund of the European Union.

\section{References}

[1] Boyanova, V., M. Stankova (2004), Hyperactivity and attention deficit, Sofia.

[2] Cotman, SW. \& N. Berchtold (2002), Exercise: a behavioral intervention to enhance brain health and plasticity. TRENDS in Neurosciences, 25.

[3] Dineva, V. (2018), Basic methodological principles and approaches in therapeutic work with families. In: Proceedings of the Annual University Scientific Conference, Vasil Levski National University.

[4] Doncheva, Y. (2014), Consolidating Functions of Bulgarian Children's Folklore Games in Preschool Age, Ruse.

[5] Ivanova, A., G. Ivanova, K. Deneva, (2015), The role of information technology in the integration of children with special educational needs and specific learning difficulties. In: ,Social Rights of Bulgarian Citizens - Problems and Perspectives', University of Ruse 'Angel Kanchev', Ruse.

[6] Ivanova, E. (2019), Formation of Social Skills and Competences through Second World Class Learning Content. In: Annual University Scientific Conference of Vasil Levski National University, Veliko Tarnovo.

[7] Ivanova, V., \& Mileva, E. (2019). Teachers' satisfaction with their professional activities in physical education and sport. In P. Hájek, \& O. Vít (Ed.), CBU International Conference Proceedings. 7, Prague: CBU Research Institute.

[8] Knudsen, E. (2004), Sensitive Periods in the Development of the Brain and Behavior. Journal of cognitive Neuroscience.

[9] Konakchieva, P. (2013), The Child and Nature. Technology organization of ecological education in kindergarten, V. Tarnovo. 
[10] Kurkchiyska, V. (2017), Inclusive education - a challenge for the primary teacher, Shumen.

[11] Marcheva, P. (2016), Artpedagogy. School. Art Therapy, Sofia.

[12] Mihova, P., M. Stankova, J. Vinarova (2015), Psychological barriers to the use of computer technologies in therapeutic practice. In: International Conference on Psychology and Society, Collection of scientific publications dedicated to the 10th anniversary of the creation of the specialty ,Psychology 'at the Plovdiv Paisii Hilendarski University, Plovdiv.

[13]Neminska R. (2018), Reflexive technology for the development of pedagogical competences in an intercultural educational environment. Online Pedagogical Forum, issue 7 .

[14] Nikolova, Sn. (2019), Principles of work for children with special educational needs, In: Proceedings of the Istanbul - Kusadasi - Izmir Travel Innovation Seminar 'Innovations in Education', University of Shumen 'Ep. K. Preslavski ‘, V. Turnovo.

[15] Ordinance on Inclusive Education, Available: http://www.mon.bg

[16]Piriova, B. (2008), Neurobiological Foundations of Child Development, Sofia.

[17][Radeva, Sn. (2016), A Social-Educational Model for Early Childhood Development - An Opportunity for Effective Care, Education and Support. In: Proceedings of the Ninth Scientific-Practical Conference on Preschool Education 'We Take the Future by Hand', Pazardzhik.

[18] Sotirov Ch. (2017), The interaction between kindergarten and families of children in need of inclusive education. Yearbook of University of Shumen 'Ep. K. Preslavski ', Volume XXI D.

[19] Stoyanova M. (2011), Models for inclusive play training for children and parents, Preschool Education Magazine, Issue no. 6.

[20] Vitanova, N. (2008), Didactic Animation, Shumen.

[21] Voinohovska, V. (2012), Information Technology and Multimedia as Factors for Increasing Student Motivation and Effectiveness of the Learning Process, Ruse

[22] World Health Organization, Available: http://www.who.int/en/

[23] Zhelezova D. (2013), Meta-regulatory competences and roles of the contemporary teacher, Ruse. 